\title{
Intended Flap Decentration in Hyperopic Laser in Situ Keratomileusis (Lasik) In Eyes with off-Centered Corneal Apex
}

\author{
Ayman Lotfy ${ }^{1 *}$, Ayman Mohamed Abdelrahman ${ }^{1}$ \\ ${ }^{1}$ Department of Ophthalmology, Zagazig University Hospitals, Zagazig, Egypt
}

Received: 12 December, 2016; Accepted: 19 December, 2016; Published: 29 December, 2016

*Corresponding author: Ayman lofty, Department of Ophthalmology, Zagazig University Hospitals, 3rd Ahmad Orabi st, Zagazig, Egypt, Tel: +201224276447; E-mail: elnadyayman@gmail.com

\begin{abstract}
Purpose: To evaluate the efficacy of flap decentration during Lasik hyperopic correction in eyes with off-centered corneal apex.

Patients and methods: In a prospective study, two groups of patients with hyperopia randomly allocated to undergo Lasik hyperopic correction. In group A (22 eyes); the flap was intentionally decentred during flap creation. In group B (22 eyes) were done without flap decentration. Complete preoperative and postoperative ophthalmic examination was done for all patients with determination of spherical equivalents by cycloplegic refraction, Uncorrected Visual Acuity (UCVA), Best Corrected Visual Acuity (BCVA) were also detected. Corneal topography was performed to all patients before and after the operation.

Results: The mean UCVA improved from $0.4 \pm 0.23$ to $0.90 \pm 0.21$ in Group $(\mathrm{A})$ and from $0.5 \pm 0.3$ to $0.8 \pm 0.2$ in Group $(\mathrm{B})$ ( $P$ value $=$ $0.023)$, and the mean BCVA, from $0.8 \pm 0.2$ to $0.97 \pm 0.1$ and from 0.8 \pm 0.2 to $0.8 \pm 0.2$, respectively ( $\mathrm{P}$ value $=0.01$ ). The mean cycloplegic spherical equivalent improved from $+3.5 \pm 0.5$ to $+0.25 \pm 0.6$ in Group (A) and from $+3.8 \pm 0.6$ to $+0.75 \pm 0.6$ in Group (B) $(P$ value $=$ 0.02 ). The safety index was 1.1 in groups and the efficacy index, 1.01 in Group 1 and 0.98 in Group 2. The enhancement rate was $20.0 \%$ and $18.4 \%$, respectively.
\end{abstract}

Conclusion: Flap decentration in hyperopic laser correction provides more predictable results in correction of hyperopia.

Keywords: Angle kappa; Topography; Decentered; Hypermetropia

\section{Introduction}

Laser in situ keratomileusis (LASIK) has been described as a means to correct hyperopia [1]. Excimer laser correction of hyperopic refractive errors involves the para central removal of a negative meniscus of stromal tissue to indirectly produce central steepening of the anterior corneal surface [2]. Many parameters, such as corneal curvature, optical zone size, and centration, must be taken into account even in correction of low grade hyperopia [3]. The complications that limit hyperopic LASIK correction include decentration and regression, which can affect the predictability, safety, and efficacy of the treatment
[4]. The initial reports of hyperopic LASIK (H-LASIK) showed mostly unsatisfactory results with considerable regression of the refractive results and a high incidence of loss of Best Corrected Visual Acuity (BCVA), primarily caused by small outer zone ablations [5]. The rapid recovery of Uncorrected Visual Acuity (UCVA) was attributed to the good centration provided by the active tracking system of the laser. This was important because long treatment time in hyperopic corrections can produce severe rotational malpositions that can produce varying results [6]. The use of planned off-center ablation to correct hyperopia may help in achieving better visual acuity than centered ablation [7].

The aim of this study is to evaluate the efficacy of corneal flap decentration during hyperopic LASIK in patients with offcentered corneal apex.

\section{Material and methods}

Forty four eyes of 22 patients with hyperopia were included in this study. The eyes were divided randomly into two groups. In group A (22 eyes); the flap was intentionally decentered during flap creation. In group B (22 eyes) were done without flap decentration. Preoperatively, a complete ophthalmic examination was performed including Uncorrected Visual Acuity (UCVA), Best Corrected Visual Acuity (BCVA), manifest and cycloplegic refraction. Spherical error ranged from +1.00 to +6.00 diopters, and refractive cylinder ranged from +0.50 to $+2.5 \mathrm{D}$. Slit lamp biomicroscopy, applanation tonometry, and corneal topography were performed to all patients. Corneal topography was used to detect off- centered corneal apex. (Fig. 1). Emmetropia was the goal in all eyes.

\section{Technique}

In group (A): Topical anesthesia was used. Flap alignment marks were placed on the cornea using a marker coated with methylene blue. A -1LC Moria M2 suction ring was used in all cases. The ring was positioned on the cornea with a slight medial decentration; suction was activated and intraocular pressure was verified to be at least $65 \mathrm{mmHg}$. Moria M2 microkeratome head 130 was used to create corneal flap. The flap was reflected 
superiorly, exposing the stromal bed. Allegrtto $400 \mathrm{~Hz}$ laser platform (Wave Light, Erlangen Germany) was used for laser ablation using T-CAT ablation profile to ensure centration of treatment around corneal apex. $6 \mathrm{~mm}$ optical zone was applied in all cases. Care was taken to ensure that the stromal bed was dry before and during the ablation and that the undersurface of the flap was protected from the laser ablation. The interface was irrigated with a balanced salt solution; the flap was replaced. Adequate flap position was verified at the slit lamp immediately after surgery.

In group (B): the hyperopic LASIK correction was done but without flap decentration. Postoperative, patients were seen 1 day, 1 week, and 1, 3, and 6 months after surgery at which times UCVA, manifest refraction, BSCVA, corneal topography, and corneal flap status were determined. For the statistical analysis of results between the groups, a chi-squared test was used with the level of significance set at $p<0.05$.

\section{Results}

Forty four eyes of 22 patients with hyperopia were underwent hyperopic LASIK correction. The eyes are divided into two groups; Group (A) of 22 eyes will go operation with intended flap decentration. Group (B) will go operation without decentration. In group (A), the preoperative UCVA ranged from 0.5 to 0.1 with mean of $0.4 \pm 0.23$ and in group (B) the UCVA ranged from 0.4 to 0.1 with mean of $0.5 \pm 0.3$ ( $P$ value $=0.43$ which is insignificant $)$. The mean BCVA was $0.8 \pm 0.2$ in group (A) and $0.8 \pm 0.4$ in group (B). The mean cycloplegic spherical equivalent was $+3.5 \pm 0.5$ and $+3.8 \pm 0.6$ respectively [Table 1 ] . Postoperatively, the mean UCVA improved from $0.4 \pm 0.23$ to $0.90 \pm 0.21$ in Group (A) and from $0.5 \pm 0.3$ to $0.8 \pm 0.2$ in Group (B) (Pvalue $=0.023$ ), and the mean BCVA, from $0.8 \pm 0.2$ to $0.97 \pm 0.1$ and from $0.8 \pm 0.4$ to $0.8 \pm$ 0.2 , respectively ( $P$ value $=0.01$ ). The mean cycloplegic spherical equivalent improved from $+3.5 \pm 0.5$ to $+0.25 \pm 0.6$ in Group (A) and from $+3.8 \pm 0.6$ to $+0.75 \pm 0.6$ in Group (B) (P value $=0.02)$. [Table 2] [Figure 1-2]. The safety index was 1.1 in both groups and the efficacy index, 1.01 in Group (A) and 0.98 in Group (B). The enhancement rate was $20.0 \%$ and $18.4 \%$, respectively.

\section{Discussion}

Laser correction of hyperopia involves the removal of a negative meniscus of stromal tissue that is thicker at the periphery than at its center. This reshapes the anterior corneal surface by steepening its curvature $[1,8]$. The initial reports of hyperopic LASIK (H-LASIK) showed mostly unsatisfactory results with considerable regression of the refractive results and a high incidence of loss of BSCVA [3-9]. In this study, one week

\section{Table 1: Patients data}

\begin{tabular}{|c|c|c|}
\hline & Group (A) & Group (B) \\
\hline No. of eyes & 22 & 22 \\
\hline UCVA & $0.4 \pm 0.23$ & $0.5 \pm 0.3$ \\
\hline BCVA & $0.8 \pm 0.2$ & $0.8 \pm 0.4$ \\
\hline Spherical equivalent & $3.5 \pm 0.5$ & $3.8 \pm 0.6$ \\
\hline
\end{tabular}

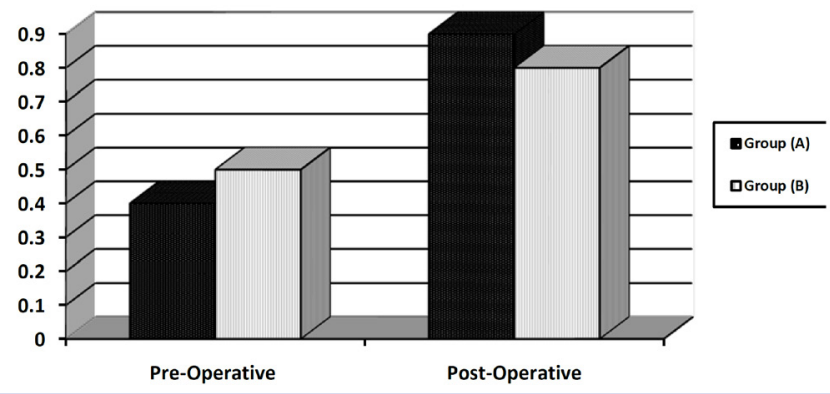

Figure 1: Pre-\& Post-operative UCVA

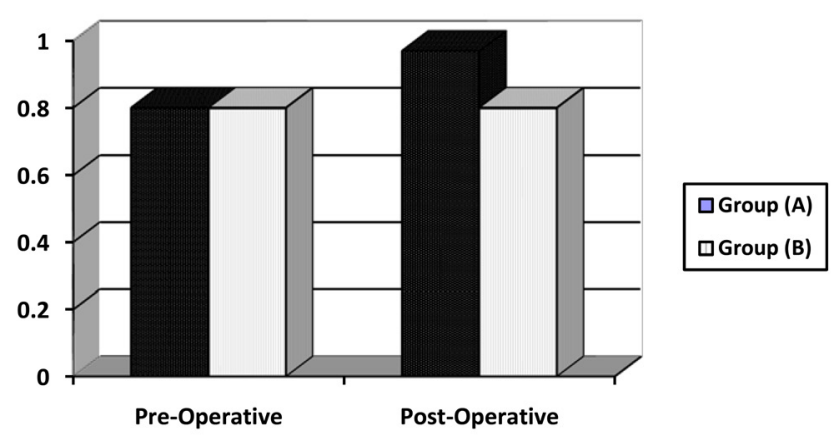

Figure 2: Preoperative and Postoperative BCVA

Table 2: Postoperative Data

\begin{tabular}{|c|c|c|c|}
\hline & Group (A) & Group (B) & (P) value \\
\hline UCVA & $0.90 \pm 0.21$ & $0.8 \pm 0.2$ & 0.023 \\
\hline BCVA & $0.97 \pm 0.1$ & $0.8 \pm 0.2$ & 0.01 \\
\hline $\begin{array}{c}\text { Spherical } \\
\text { equivalent }\end{array}$ & $0.25 \pm 0.6$ & $+0.75 \pm 0.6$ & 0.02 \\
\hline
\end{tabular}

after hyperopic LASIK correction, the mean UCVA was 0.9 in group A which undergone the operation with flap decentration while it was 0.8 in group B without flap decentration with significant statistically difference $(p=0.023)$. The group with flap decentration showed BCVA postoperatively 0.97 and the patients of other group had mean postoperative BCVA 0.8 with high significant difference $(p=0.01)$.

Zadok et al [10] on their study on 92 eyes undergone hyperopic LASIK correction, they divided the patients into 3 groups according to the degree of hyperopia: low hypeopia $(+3.00$ D), moderate hypeopia (+3 - +6.00 D) \& high hyperopia ( $\geq$ +6 D). They reported that spherical equivalent postoperatively was +0.33 in low hyperopic group, $+0.21 \mathrm{D}$ in moderate group $\&+1.62$ D in high group. Carlos and Maria [11] compared the results of hyperopic laser in situ keratomileusis (LASIK) with a $5.9 \mathrm{~mm}$ optical zone (OZ) to those with smaller zones (4.4 to 5.5 $\mathrm{mm}$ ). They operated 147 cases with $5.9 \mathrm{~mm}$ optical zone and 679 cases with smaller zone. They found that hyperopic LASIK with a $5.9 \mathrm{~mm} \mathrm{OZ}$ in eyes with low, moderate and high hyperopia is more stable, predictable, and safer than hyperopic LASIK with smaller optical zone. 
Williams et al [12] operated 49 hyperopic eyes with mean preoperative hyperopia $+3.44 \mathrm{D}$. They also detect the preoperative $\mathrm{K}$ reading for all patients. They reported loss of 1 or more line of BCVA in 11 patients and they concluded that an increased incidence of loss of BSCVA and decreased patient satisfaction was associated with a preoperative $\mathrm{K}$ value greater than 44.0 D in hyperopic LASIK. Fernando et al [13], in their retrospective study, evaluated hyperopic LASIK results over 1 year. They divided the patients into 2 groups (Group $1:<+3.50$ D. \& Group $2>+3.60$ D). they reported that the mean UCVA improved from 0.50 to 0.9 in Group 1 and from 0.5 to 0.80 in Group 2 and the mean BCVA, from 0.8 to 0.930 .1 and from 0.8 to 0.9 respectively. The mean spherical equivalent improved from + $2.5 \pm 0.8$ to $+0.1 \pm 0.5$ in Group 1 and from $+4.5 \pm 0.6$ to $+0.4 \pm 0.6$ in Group 2. The safety index was 1.1 in groups and the efficacy index, 1.01 in Group 1 and 0.98 in Group 2.

\section{Conclusion}

The results of this study confirm that flap decentration during hyperopic LASIK correction has a better results with higher safety and efficacy in patients with off-centered corneal apex.

\section{Acknowledgments}

Authors acknowledge the immense help received from the scholars whose articles are cited and included in references of this manuscript. The authors are also grateful to authors / editors / publishers of all those articles, journals and books from where the literature for this article has been reviewed and discussed.

\section{Author contributions}

The idea of the work was combined thinking of both authors. All the cases were operated by the same surgeon (AMA), the data were collected and evaluated by the corresponding author (AL).

\section{Disclosure}

This research received no specific grant from any funding agency in the public, commercial or not-for-profit sectors. The authors have no financial interest in the subject of the study and there is no conflict of interest.

\section{References}

1. Plaza-Puche AB, Yebana P, Arba-Mosquera S, Alió JL. Three-year followup of hyperopic LASIK using a 500-Hz excimer laser system. J Refract Surg. 2015;31(10):674-82. doi: 10.3928/1081597X-20150928-06.

2. Mujtaba AQ, Cynthia JR, Ashraf MM, Jay SP. Topographic and biomechanical differences between hyperopic and myopic laser in situ keratomileusis. J Cataract Refract Surg. 2005;31(1):48-60.

3. de Ortueta D, Arba Mosquera S. Topographic stability after hyperopic LASIK. J Refract Surg. 2010;26(8):547-54. doi: 10.3928/1081597X20100225-01.

4. Katz T, Wagenfeld L, Galambos P, Darrelmann BG, Richard G, Linke SJ. LASIK versus photorefractive keratectomy for high myopic ( $>3$ diopter) astigmatism. J Refract Surg. 2013;29(12):824-31. doi: 10.3928/1081597X-20131029-03.

5. Salomon Esquenazi, Viet Bui and Olga Bibas. Surgical Correction of Hyperopia. Surv Ophthalmol. 2006;51(4):381-418.

6. Barraquer C. In situ keratomileusis with Excimer laser for hypermetropia. Preliminary results. Arch Soc Esp Oftalmol. 2000;75(3):143.

7. Bauerberg JM. Centered vs. inferior off-center ablation to correct hyperopia and presbyopia. J Refract Surg. 1999;15(1):66-9.

8. Ditzen K, Fiedler J, Pieger S. Laser in situ keratomileusis for hyperopia and hyperopic astigmatism using the Meditec MEL 70 spot scanner. J Refract Surg. 2002;18(4):430-4.

9. McGhee CN, Ormonde S, Kohnen T. The surgical correction of moderate hypermetropia: the management controversy. Br J Ophthalmol 2002; 86(7):815-22.

10.Zadok D, Raifkup F, Landau D, Joseph F. Long-term evaluation of hyperopic laser in situ keratomileusis. J Cataract Refract Surg 2003;29(11):2181-88.

11. Carlos JA, Marı́a JC. Comparison of optical zones in hyperopic laser in situ keratomileusis: $5.9 \mathrm{~mm}$ versus smaller optical zones. J Cataract Refract Surg. 2000;26(8):1137-46.

12. Williams LB, Dave SB, Moshirfar M. Correlation of visual outcome and patient satisfaction with preoperative keratometry after hyperopic laser in situ keratomileusis. J Cataract Refract Surg. 2008;34(7):10838. doi: 10.1016/j.jcrs.2008.03.018.

13. Fernando L, Ahmed G, Jose-Manuel B, Clara M, Julio B. One-year results of excimer laser in situ keratomileusis for hyperopia. J Cataract Refract Surg. 2009;35(7):1156-65. doi: 10.1016/j.jcrs.2009.03.014. 